\title{
Comparison of lipoprotein and apolipoprotein levels in cord blood
}

\author{
Ruqaya Aziz'1, Mehbooba Beigh², Qazi Najeeb ${ }^{1 *}$, Ashaqullah Bhat ${ }^{1}$, Irshad ${ }^{2}$
}

\begin{abstract}
${ }^{1}$ Department of Biochemistry, ${ }^{2}$ Department of Gynecology and Obstetrics, SKIMS Medical College, Bemina, Srinagar,
\end{abstract} Jammu and Kashmir, India

Received: 21 January 2019

Accepted: 05 March 2019

\section{*Correspondence:}

Dr. Qazi Najeeb,

E-mail: qnajeeb@gmail.com

Copyright: (c) the author(s), publisher and licensee Medip Academy. This is an open-access article distributed under the terms of the Creative Commons Attribution Non-Commercial License, which permits unrestricted non-commercial use, distribution, and reproduction in any medium, provided the original work is properly cited.

\begin{abstract}
Background: Hyperlipidemia is the primary risk factor for coronary artery disease and subsequently leading to morbidity and mortality in adulthood. It is a well-known fact that coronary artery disease can initiate in the fetal stage itself. The present study was planned to analyse cord blood lipoproteins and apolipoproteins levels and its association with gender and birth weight.

Methods: This cross-sectional study was conducted in the Department of Biochemistry, in collaboration with Department of Gynecology and Obstetrics at SKIMS Medical College and Hospital, Bemina, Srinagar. A total 200 pregnant women who delivered by normal vaginal delivery and caesarean section were included in the study. $10 \mathrm{ml}$ of umbilical cord blood was collected in a plain vial from the placental end within five minutes of delivery and serum lipoprotein and Apo-lipoprotein levels were measured.

Results: Out of 200 newborns 102 were males and 98 were females. Statistically significant difference was seen in parameters Apo A1, Apo B, Atherogenic index (Apo B/Apo A1) and LDL between the genders rest of the parameters were statistically. Also 32 newborns $(16.0 \%)$ had <2500, 152 (76.0\%) new born had 2500-4000 and 16(8.0\%) > 4000 grams birth weight. The mean lipoprotein and Apo-lipoprotein levels in these new born were compared between the groups. The mean serum levels of TC, TG, LDL and HDL were statistically significant $(<0.05)$ between the three groups were as Apo A1, Apo B, Atherogenic index (Apo B/Apo A1) and VLDL was insignificant (>0.05) respectively.

Conclusions: CVD being a leading cause of morbidity and mortality in the developing countries, early screening of the at risk babies i.e. low birth weight newborns using cord blood lipoproteins and apolipoproteins levels helps in primordial and primary prevention of diseases.
\end{abstract}

Keywords: Apolipoprotein, Birth weight, Cord blood, Lipoprotein

\section{INTRODUCTION}

Hyperlipidemia is the primary risk factor for coronary artery disease and subsequently leading to morbidity and mortality in adulthood. The progression of coronary artery disease initiates early in life and progresses silently for years. It is a well-known fact that coronary artery disease can initiate in the fetal stage itself.' The 'fetal origins hypothesis' indicates that intense and continuous impact of factors related to the fetal health including coronary artery disease on the process of chronic diseases in adultlife. ${ }^{2}$ Significant evidence have proven that children with hypercholesterolemia are at high risk of subsequent coronary artery disease. ${ }^{3-6}$ Epidemiological studies have shown a strong independent association between serum cholesterol and coronary artery disease. ${ }^{7}$ Maternal dyslipidemia has been related to increase early coronary artery disease and significant surge in fatty 
streaks in human newborns. ${ }^{8}$ There is a well-established fact that cord sera contains all characterized adult lipoproteins and apolipoproteins and chronic pattern of atherogenic lipoprotein metabolism is associated with fetal growth restrictions. ${ }^{9}$ Elevated lipoprotein levels in childhood continue into adult life and raised Apo B levels in young adults have been associated to coronary artery disease in progressive years of life. ${ }^{10}$ Early stage of life can be seen as an opportunity to initiate preventive interventions to change risk factors for cardiovascular diseases.

Recent studies showed that detection of these markers (lipoproteins and apolipoproteins levels) in the umbilical cord blood from the newborns could recognize neonates at a higher risk for coronary heart disease. ${ }^{11}$ As such; limited studies exist on the difference of the cord blood concentrations according to the birth weight and gender of the newborns.

The present study was planned to analyse cord blood lipoproteins and apolipoproteins levels and its association with gender and birth weight.

\section{METHODS}

This cross-sectional study was conducted in the Department of Biochemistry, in collaboration with Department of Gynecology and Obstetrics at SKIMS Medical College and Hospital, Bemina, Srinagar.

\section{Inclusion criteria}

- A total 200 pregnant women who delivered by normal vaginal delivery and caesarean section and were on supplementation of vitamins, iron, folic acid and calcium with gestational age between 35-42 weeks were randomly included in the study after obtaining informed and written consent.

\section{Exclusion criteria}

- Pregnant women with history of maternal hypertension either before or during pregnancy, preeclampsia or eclampsia, history of paternal or maternal hyperlipidemia, maternal CVD, pregestational or gestational diabetes, any history of maternal drug use during or before pregnancy including women receiving glucocorticoid therapy for fetal lung maturation or a history of smoking were excluded.

Maternal and newborns details were noted in a predesigned proforma. $10 \mathrm{ml}$ of umbilical cord blood was collected in a plain vial from the placental end within five minutes of delivery and then the serum was separated by centrifugation. Serum lipoprotein and Apo-lipoprotein levels were measured using an enzymatic method in an auto analyser (Beckman Coulter AU 5800). Atherogenic index (AI) was calculated as ratio of Apo B to Apo A1. Birth weight was measured with an electronic scale. Newborns were divided into 3 groups according to their birth weight, less than 2500 grams as group I, 2500-4000 grams as group II and more than 4000 grams as group III.

\section{Statistical analysis}

Data was analysed with SPSS 20.0 for Windows (SPSS Inc., Chicago, IL, USA). Results were expressed as mean \pm SD.

The student's t-test, analysis of variance (ANOVA) and Chi square test was used to make statistical comparisons. A P-value $<0.05$ was considered statistically significant.

\section{RESULTS}

A total of 200 newborns [102 (51.0\%) males and 98 $(49.0 \%)$ females] were included in the study.

Table 1: Demographical profile of mothers.

\begin{tabular}{|c|c|c|c|c|c|}
\hline Parameters & & Male new born & Female new born & Chi-square & P-value \\
\hline \multirow{2}{*}{ Life style } & Active & $72(70.6 \%)$ & $86(87.8 \%)$ & \multirow{2}{*}{8.878} & \multirow{2}{*}{$<0.01$} \\
\hline & Sedentary & $30(29.4 \%)$ & $12(12.2 \%)$ & & \\
\hline \multirow{2}{*}{$\begin{array}{l}\text { Socio-economic } \\
\text { status }\end{array}$} & Lower class & $30(29.4 \%)$ & $48(49.0 \%)$ & \multirow{2}{*}{8.044} & \multirow{2}{*}{$<0.01$} \\
\hline & Middle class & $72(70.6 \%)$ & $50(51.0 \%)$ & & \\
\hline \multirow{2}{*}{ Occupation } & House wife & $100(98.0 \%)$ & $98(100 \%)$ & \multirow{2}{*}{1.941} & \multirow{2}{*}{$>0.05$} \\
\hline & Working & $02(2.0 \%)$ & $0(0.0 \%)$ & & \\
\hline \multirow{3}{*}{ Order of the issue } & $1^{\text {st }}$ & $42(41.2 \%)$ & $52(53.1 \%)$ & \multirow{3}{*}{3.042} & \multirow{3}{*}{$>0.05$} \\
\hline & $2^{\text {nd }}$ & $34(33.3 \%)$ & $24(24.5 \%)$ & & \\
\hline & $\geq 3^{\text {rd }}$ & $26(25.5 \%)$ & $22(22.4 \%)$ & & \\
\hline \multirow{2}{*}{ Gestational age } & Term & $92(90.2 \%)$ & $96(98.0 \%)$ & \multirow{2}{*}{5.340} & \multirow{2}{*}{$<0.05$} \\
\hline & Pre-term & $10(9.8 \%)$ & $02(2.0 \%)$ & & \\
\hline \multirow{2}{*}{ Mode of delivery } & C-section & $24(23.5 \%)$ & $10(10.2 \%)$ & \multirow{2}{*}{6.289} & \multirow{2}{*}{$<0.05$} \\
\hline & Normal & $78(76.5 \%)$ & $88(89.8 \%)$ & & \\
\hline
\end{tabular}


Table 2: Comparison of genders of newborns.

\begin{tabular}{|l|l|l|l|}
\hline Parameters & Male $(\mathbf{n}=\mathbf{1 0 2})$ & Female $(\mathbf{n = 9 8})$ & Sig. $(\mathbf{p}$-value $)$ \\
\hline Apo A1 & $48.31 \pm 21.79$ & $67.27 \pm 19.73$ & 0.0001 \\
\hline Apo B & $29.07 \pm 10.00$ & $19.62 \pm 6.81$ & 0.0001 \\
\hline AI (ApoB/ApoA1) & $0.60 \pm 0.45$ & $0.29 \pm 0.34$ & 0.0001 \\
\hline Total Cholesterol & $62.47 \pm 17.08$ & $59.80 \pm 17.03$ & 0.435 \\
\hline TG & $55.39 \pm 23.46$ & $52.53 \pm 21.35$ & 0.526 \\
\hline HDL & $18.88 \pm 10.14$ & $20.04 \pm 9.49$ & 0.557 \\
\hline LDL & $53.66 \pm 11.28$ & $35.63 \pm 10.33$ & 0.0001 \\
\hline VLDL & $6.65 \pm 4.51$ & $5.14 \pm 3.78$ & 0.075 \\
\hline
\end{tabular}

Table 3: Comparison of lipoprotein and apolipoprotein in 3 study groups as per birth weight.

\begin{tabular}{|c|c|c|c|c|c|}
\hline Parameters & Group-I (n=32) & Group-II (n=152) & Group-III (n=16) & Total $(n=200)$ & Sig. (p-value) \\
\hline Apo A1 & $53.56 \pm 20.25$ & $58.88 \pm 22.82$ & $53.50 \pm 28.44$ & $57.60 \pm 22.79$ & $0.610^{*}$ \\
\hline Apo B & $21.62 \pm 15.98$ & $19.11 \pm 6.52$ & $16.98 \pm 3.36$ & $19.34 \pm 8.55$ & $0.409 *$ \\
\hline $\begin{array}{l}\text { Atherogenic index } \\
\text { (ApoB/ApoA1) }\end{array}$ & $0.40 \pm 0.78$ & $0.32 \pm 0.28$ & $0.31 \pm 0.11$ & $0.33 \pm 0.37$ & $0.225^{*}$ \\
\hline Total Cholesterol (TC) & $70.69 \pm 15.78$ & $58.43 \pm 15.87$ & $68.00 \pm 22.92$ & $61.16 \pm 17.02$ & $0.015 * *$ \\
\hline TG & $40.44 \pm 21.93$ & $55.45 \pm 21.23$ & $67.25 \pm 24.11$ & $53.99 \pm 22.38$ & $0.010 * *$ \\
\hline HDL & $25.19 \pm 10.77$ & $18.28 \pm 8.53$ & $19.12 \pm 15.48$ & $19.45 \pm 9.80$ & $0.036 * *$ \\
\hline LDL & $41.81 \pm 8.15$ & $35.47 \pm 10.97$ & $41.38 \pm 11.57$ & $36.96 \pm 10.85$ & $0.050 * *$ \\
\hline VLDL & $6.81 \pm 3.88$ & $5.55 \pm 4.34$ & $7.50 \pm 3.33$ & $5.91 \pm 4.22$ & $0.302 *$ \\
\hline
\end{tabular}

Out of 102 male newborns, $70.6 \%$ mothers were physically active and $29.4 \%$ were sedentary, $29.4 \%$ mothers were having low socio-economic status and $70.6 \%$ had middle socio-economic status, $90.2 \%$ were term gestation newborns and $9.8 \%$ were pre-term newborns, $76.5 \%$ were born through normal mode of delivery and $23.5 \%$ through casserian section compared with 98 female newborns were $87.8 \%$ were active and $12.2 \%$ sedentary mothers, $49.0 \%$ mothers were having low socio-economic status and $51.0 \%$ had middle socioeconomic status, $98.0 \%$ were term gestation newborns and $2.0 \%$ were pre-term newborns, $89.8 \%$ were born through normal mode of delivery and $10.2 \%$ through caesarean section which was statistically significant $(p<0.05)$. Also, when the comparison of occupation and order of issue between mothers of male newborns with mothers of female newborns was statistically insignificant $(\mathrm{p}>0.05)$ as shown in Table 1.

Out of 200 newborns102 were males and 98 were females. Statistically significant difference was seen in parameters Apo A1, Apo B, Atherogenic index (Apo $\mathrm{B} / \mathrm{Apo} \mathrm{A} 1$ ) and LDL between the genders rest of the parameters were statistically insignificant as shown in Table 2.

Also 32 newborns (16.0\%) had <2500, 152 (76.0\%) new born had 2500-4000 and 16(8.0\%) >4000 grams birth weight. The mean lipoprotein and Apo-lipoprotein levels in these new born were compared between the groups as shown in Table 3.
The mean serum levels of TC, TG, LDL and HDL were statistically significant $(<0.05)$ between the three groups were as Apo A1, Apo B, Atherogenic index (Apo B/Apo A1) and VLDL was insignificant (>0.05) respectively.

\section{DISCUSSION}

Estimation of cord blood lipoproteins and apolipoproteins in newborns could be predictive for lipoprotein disorders and cardiovascular diseases (CVD) in adulthood since low birth weight (LBW) is an important risk factor for CVD and other non-communicable diseases. This study showed that the cord blood lipid profiles in male and female newborns were not significantly different from each other; but higher values of total cholesterol, TG, HDL, and VLDL were noted in the male neonate. This was in concordance with few other studies including Anderson et al and Tsang et al which showed no significant changes in the cord blood lipid profile in terms of gender. ${ }^{12,13}$ However, LDL levels were higher in male newborns than female which is in contrast with study by Esfarjani SV et al. ${ }^{14}$

It is well-recognised fact that low Apo A1 and/or increased Apo B are associated with increased cardiovascular risk. Elevated Apo B levels and raised Atherogenic index (AI) in young adults are linked with cardiovascular disease in later life. ${ }^{15}$ In present study Apo A1levels in cord blood were higher in female newborns as shown in study by Bastida $\mathrm{S}$ et al, and Apo B and Atherogenic index was higher in male counterparts which 
was not in accordance of Kharb et.al who showed more levels in female neonates. ${ }^{16,17}$

Birth weight is an amount of fetal growth which summaries body size, body length and subcutaneous fat. Studies have shown that newborns that have a low birth weight at birth tends to develop metabolic syndrome, hypertension, hyperinsulinemia, dyslipidemia and obesity in adult life. ${ }^{18}$ In the present study Apo A1, Apo B levels and atherogenic index had non-significant association with birth weight of all the three groups. As reported by Radunovic et al. who had higher Apo B levels and Atherogenic index in low birth weight (LBW) newborns as compared to normal newborns, present study showed the similar results. ${ }^{19}$ Total cholesterol, LDL, and HDL levels in LBW (group-I) and high birth weight(group-III) newborns were significantly higher than in normal weight (group-II) newborns were as TG and VLDL were significantly higher in (group-III) neonates (Table 3).This proves that fetal growth retardation establishes a lifelong irreversible atherogenic process and male newborns with low birth weight tends to have higher atherogenic profile.

\section{CONCLUSION}

CVD being a leading cause of morbidity and mortality in the developing countries, early screening of the at risk babies i.e. low birth weight newborns using cord blood lipoproteins and apolipoproteins levels helps in primordial and primary prevention of diseases. Also, many adult diseases, including metabolic syndrome, hypertension, hyperinsulinemia, dyslipidemia and obesity begin in early neonatal life and collected risk factors path to adulthood. So, these factors can be altered and can be modified by early lifestyle interventions particularly in male newborns. Since the development of vascular damage is not a onetime affair and needs long term environment for a disease to the process, it opens up new opportunities to proceed for further research to track the lipid levels of the newborns with respect to weight at the time of birth and note the gender predisposition.

\section{Funding: No funding sources}

Conflict of interest: None declared

Ethical approval: The study was approved by the Institutional Ethics Committee

\section{REFERENCES}

1. Rifai N, Bachorik PS, Albers JJ. Lipids, lipoproteins and apolipoproteins. In: Carl AB, Edward RA, eds. Teitz Textbook of Clinical Chemistry. $3^{\text {rd }}$ ed. USA: WB Saunders; 1999:826-830.

2. Barker DJP. The intrauterine origins of cardiovascular disease. Acta Paedia. 1993;391:93-9.

3. Goldstein JL, Albers JJ, Schrott HG, Hazzard WR, Bierman EL, Motulsky AG. Plasma lipid levels and coronary heart disease in adult relatives of newborns with normal and elevated cord blood lipids. Am J Hum Genet. 1974;26:727-35.
4. Gozlan O, Gross D, Gruener N. Lipoprotein levels in newborns and adolescents. Clin Biochem. 1994;27:305-6.

5. Lakhtakia JR, Dogra J, Mathur HC, Mishra SN. Serum lipid in neonatal cord blood in families with essential hypertension. Indian Pediatr. 1990;27:11013.

6. Low PS, Saha N, Tay JS, Hong S. Ethnic variation of cord plasma apolipoprotein levels in relation to coronary risk level: a study in three ethnic groups of Singapore. Acta Paediatr. 1996;85:1476-82.

7. Rajasekhar D, Saibaba KSS, Srinivasa Rao PVLN, Latheef SAA, Subramanyam G. Lipoprotein (a): Better assessor of coronary heart disease risk in South Indian population. Ind J Clin Biochem. 2004;19:53-9.

8. Napoli C, Nigris FD, Welch JS, Calara FB, Stuart RO, Glass CK, et al. Maternal hypercholesterolemia during pregnancy promotes early atherogenesis in LDL receptor deficient mice and alters aortic gene expression determined by microarray. Circulation. 2002;105:1360-7.

9. Conathy WJ, Lane DM. Studies on the apolipoproteins and lipoproteins of cord serum. Pediatr Res. 1980;14:757-61.

10. Klag MJ, Ford DE, Mead LA, He J, Whelton PK, Liang KY, et al. Serum cholesterol in young men and subsequent cardio vascular disease. N Engel J Med. 1993;328:313-8.

11. Casanueva V, Cid X, Chiang MT, Molina M, Ferrada MC, Perez R. Lipids, lipoproteins and apolipoproteins in normal newborns. Revista Med Chile. 1998;126(9):1073-8.

12. Anderson GE, Hansen BF. Neonatal hypertryglyceridemia, a new index of antepartum and intrapartum fetal distress. Acta Pediatr Scand. 1976;65:369-73.

13. Tsang RC, Glueck CJ. Pediatric type hyperlipoproteinemia. Effect of diet on plasma cholesterol in the first year of life. Am J Clin Nutr. 1972;25:224-30.

14. Vaziri Esfarjani Sh, Iravani E, Razzaghi Azar M. Determination of the lipid profile of cord blood in neonates and its correlation with maternal age in Iran. J Compr Ped. 2013;4(1):72-6.

15. Adult Treatment Panel III. Executive summary of the third report of the National Cholesterol Education Program (NCEP). Expert panel on detection, evaluation and treatment of high blood cholesterol in adults (Adult Treatment Panel III) JAMA. 2001;285:2486-97.

16. Bastida S, Sánchez-Muniz FJ, Cuesta C, Perea S, Ureta A. Serum apolipoproteins A-I and B in male and female full-term newborns of the Toledo study (Spain). Acta Paediatr. 1996;85(6):750-2.

17. Kharb S, Kaur R, Singh V, Sangwan K. Birth weight, cord blood lipoprotein and apolipoprotein levels in Indian newborns. Int $\mathbf{J}$ Prev Med. 2010;1(1):29-33. 
18. Dolphin PJ. Breckenridge WC, Dolphin MA, Tan MH. The lipoproteins of human Umbilical cord blood, apolipoproteins and lipid levels. Atherosclerosis. 1985;51:109-22.

19. Radunovic N, Kuczynski E, Rosen T. Plasma apolipoprotein AI and B concentrations in growth retarded fetuses. A link between low birth weight and adult atherosclerosis. J Clin Endocrinol Metab. 2000;85:85-8.

Cite this article as: Aziz R, Beigh M, Najeeb Q, Bhat A, Irshad. Comparison of lipoprotein and apolipoprotein levels in cord blood. Int J Reprod Contracept Obstet Gynecol 2019;8:1398-402. 